\title{
KEPATUHAN MASYARAKAT DI KABUPATEN GRESIK DALAM MENGURUS IZIN MENDIRIKAN BANGUNAN
}

\author{
Ikrima Iffah Sochifah ${ }^{1)}$, Ronny Durrotun Nasihien ${ }^{2)}$ \\ ${ }^{1)}$ Prodi Teknik Sipil, Universitas Narotama Surabaya, ikrimasochifah@yahoo.com. \\ 2)Prodi Teknik Sipil, Universitas Narotama Surabaya,ronny.durrotun@narotama.ac.id
}

\begin{abstract}
ABSTRAK
Kita ketahui bahwa peraturan IMB berlaku dan mengikat bagi semua pihak yang melakukan kegiatan pembangunan. Pemerintah Kabupaten Gresik menerapkan pemberlakuan IMB sebagai alat pengendali tata ruang wilayah yang ditetapkan melalui Peraturan Daerah Nomor 28 Tahun 2011 tentang Bangunan Gedung, yang diatur lebih lanjut dalam Peraturan Daerah Nomor 8 Tahun 2012 tentang Penanaman Modal di Kabupaten Gresik, namun di lapangan pemberlakuan peraturan ini belum optimal ditaati oleh masyarakat selaku pemilik atau pengguna bangunan.Berdasarkan hasil penelitian yang telah dibahas diatas, maka dapat ditarik kesimpulan bahwa tingkat kepatuhan masyarakat dalam mengurus izin mendirikan bangunan di Kabupaten Gresik sebesar 71,32\%. Untuk meningkatkan kepatuhan masyarakat dalam mengurus izin sebelum mendirikan sebuah bangunan, dengan cara memberikan sanksi-sanksi terkait setelah adanya sosialisasi. Pemda harus benar-benar lebih ketat dalam pemberian sanksi, agar hal ini dapat menimbulkan efek jera terhadap masyarakat. Sehingga bangunan liar yang ada di Kabupaten Gresik tidak semakin bertambah, dan tercipta masyarakat yang patuh dengan peraturan.
\end{abstract}

Kata Kunci : Bangunan, IMB, kepatuhan.

\section{PENDAHULUAN}

Bangunan gedung sebagai tempat manusia dalam melakukan kegiatannya, mempunyai peran yang sangat strategis dalam pembentukan watak, perwujudan produktivitas, serta jati diri. Selain itu juga bangunan gedung berfungsi sebagai tempat manusia melakukan kegiatannya, baik untuk hunian atau tempat tinggal, keagamaan, usaha, social budaya maupun kegiatan khusus.

Dalam rangka menciptakan tata ruang wilayah sesuai rencana yang telah ditetapkan, maka salah satu hal yang memegang peranan cukup penting adalah Izin Mendirikan Bangunan (IMB) yang merupakan izin untuk mendirikan, memperbaiki, menambah, mengubah atau merenovasi suatu bangunan (Awan, 2010).

Dasar hukum, IMB adalah Undang-Undang No.28 Tahun 2002 tentang Bangunan Gedung serta Peraturan Menteri DalamNegeri No. 32 Tahun2010 tentang Pedoman Pemberian Izin Mendirikan Bangunan, oleh karena itu maka IMB merupakan salah satu prosedur perizinan yang penting dan wajib dipenuhi oleh setiap masyarakat yang akan melakukan pembangunan agar desain bangunan dan pelaksanaannya sesuai dengan rencana tata ruang yang ada dan syarat-syaratlain yang berlaku. IMB bagi masyarakatakan memberikan rasa aman berupa jaminankepastian hukum terhadap bangunannya untukterhindar dari gugatan pihak lain setelahbangunan berdiri (Sutedi, 2011).

Pemerintah Kabupaten Gresik menerapkan pemberlakuan IMB sebagai alat pengendali tataruang wilayah yang ditetapkan melalui Peraturan Daerah Nomor 28 Tahun 2011 tentang Bangunan Gedung, yang diatur lebih lanjut dalam Peraturan Daerah Nomor 8 Tahun 2012 tentang Penanaman Modal di Kabupaten Gresik, namun 


\section{NAROTAMA JURNAL TEKNIK SIPIL \\ e-ISSN: 2460-3430 \\ VOLUME 3 NOMOR 1 JUNI 2019}

di lapangan pemberlakuan peraturan ini belum optimal ditaati oleh masyarakat selaku pemilik atau pengguna bangunan. Masih banyak pelanggaran yang terjadi dalam melakukan aktivitas pembangunan. Sehingga dapat dilihat bahwa penerimaan informasi yang diterima masyarakat masih kurang.

Kita ketahui bahwa peraturan IMB berlaku dan mengikat bagisemua pihak

yang melakukan kegiatan pembangunan. Pembangunan yang meliputi pendirian/mengubah dan atau menambahbangunan di seluruh wilayah Kabupaten Gresik,baik dari unsur pemerintah, swasta maupunmasyarakat atau perorangan. Kegiatanmendirikan bangunan yang dilakukanpemerintah dan swasta karena jumlah yangterbatas, jenis, tempat dan fungsinya jelas, makapengawasan lebih mudah dilaksanakan. Namunbagi kegiatan pendirian bangunan yangdilakukan oleh masyarakat atau perorangankarena jumlahnya yang banyak dan tersebar,maka pengawasannya tentu saja akanmenghadapi berbagai kendala. Dalam hal inilahdiperlukan adanya pemahaman dan penerimaan masyarakat terhadap informasi IMB untukkemudian diharapkan timbul kepatuhan darimasyarakat terhadap tata ruang wilayah danmengikuti prosedur membangun sesuaiperaturan IMB yang berlaku.

Dilihat dari berbagai kenyataan kepatuhan masyarakat di Kabupaten Gresik maka peneliti tertarik untuk mengkaji lebih jauh mengenai masalah ini.

\section{PERMASALAHAN DAN BATASAN MASALAH}

Dengan merujuk pada latar belakang di atas maka dirumuskanlah masalah seperti, bagaimana cara yang bisa dilakukan untuk meningkatkan kepatuhan masyarakat dalam mengurus izin sebelum mendirikan sebuah bangunan?

Mengingat permasalah dalam pelaksanaan evaluasi yang begitu luas maka penulis memberikan batasan, yaitu :

1. Sampling data bangunan gedung sejumlah 47pengguna/pemilik bangunan kepentingan umum yang menyebar di Kabupaten Gresik.

2. Data yang diambil merupakan data kuisioner yang telah disiapkan dan data hasil observasi di lapangan.

\section{METODE PENELITIAN}

Jenis penelitian yang digunakan adalah metode kuantitatif dengan menggunakan metode survei. Creswell (2010) menjelaskan bahwa metode survei berusaha memaparkan secara kuantitatif kecenderungan sikap atau opini dari suatu populasi tertentu dengan meneliti suatu sempel dari populasi dengan tujuan menggeneralisasi populasi tersebut berdasarkan sampel yang ditentukan (h.18). Metode survei merupakan penelitian kuantitatif yang menggunakan kuesioner sebagai instrumen pengumpulan data (Anggara, 2015, h.21).

Metode penelitian kuantitatif dapat diartikan sebagai metode penelitian yang berlandaskan pada filsafat positivisme, digunakan untuk meneliti pada populasi atau sampel tertentu, teknik pengambilan sempel umumnya dilakukan secara random, pengumpulan data menggunakan instrumen penelitian, analisis data bersifat kuantitatif/statistik dengan tujuan untuk menguji hipotesis yang telah ditetapkan (Sugiyono, 2013:13) 


\section{NAROTAMA JURNAL TEKNIK SIPIL \\ e-ISSN: 2460-3430 \\ VOLUME 3 NOMOR 1 JUNI 2019}

\section{HASIL DAN PEMBAHASAN}

Perwujudan tujuan peraturan daerah yang dibuat di Kabupaten Gresik yaitu agarmasyarakat dengan tertib mengurus izin-izin yang ada sehingga tidak timbul bangunan liar. Sebagai contoh mengurus Izin Mendirikan Bangunan sebelum bangunan itu berdiri, IMB mempunyai fungsibangunan yang direncanakan sesuai dengan Tata Ruang yang telah ditentukan. Selain itu, adanya IMB menunjukkan bahwa rencana kostruksi bangunan tersebut juga dapat dipertanggungjawabkan dengan maksud untuk kepentingan bersama. Beberapa indikator seperti mengenai tentang Izin Pemanfaatan Ruang (IPR) dan IMB diberikan kepada responden sehingga mendapat jawaban seperti tabel berikut :

Tabel 1 :Izin Pemanfaatan Ruang sudah di urus sebelum bangunan berdiri

\begin{tabular}{|c|l|c|c|c|c|}
\hline No & Tanggapan Responden & $\begin{array}{c}\text { Skor } \\
(\mathrm{x})\end{array}$ & $\begin{array}{c}\text { Frekuensi } \\
(\mathrm{f})\end{array}$ & f.x & $\begin{array}{c}\text { Presentase } \\
(\%)\end{array}$ \\
\hline 1 & Sangat Setuju & 5 & 10 & 50 & 21,28 \\
\hline 2 & Setuju & 4 & 22 & 88 & 46,81 \\
\hline 3 & Kurang Setuju & 3 & 9 & 27 & 19,15 \\
\hline 4 & Tidak Setuju & 2 & 6 & 12 & 12,77 \\
\hline 5 & Sangat Tidak Setuju & 1 & 0 & 0 & 0,00 \\
\hline \multicolumn{2}{|c|}{ TOTAL (N) } & 47 & 177 & 100 \\
\hline \multicolumn{2}{|c|}{ Rata - rata skor $=\frac{\text { Jumlah f.x }}{\text { N }}$} & $=\underline{177}$ & 3,77 & \\
\hline
\end{tabular}

Sumber : Data Olahan

Dari data diatas dapat dilihat bahwa 10 responden atau 21,28\% menjawab sangat setuju, 22 responden atau 46,81\% menjawab setuju, 9 responden atau 19,15\% menjawab kurang setuju, 6 responden atau 12,77\% menjawab tidak setuju. Maka dari itu dapat ditarik kesimpulan bahwa masyarakat setuju jika Izin Pemanfaatan Ruang sudah di urus sebelum bangunan berdiri dengan rata-rata skor 3,77.

Tabel 2 :Bangunan yang terbangun sudah mempunyai IMB

\begin{tabular}{|c|l|c|c|c|c|}
\hline No & Tanggapan Responden & $\begin{array}{c}\text { Skor } \\
(\mathrm{x})\end{array}$ & $\begin{array}{c}\text { Frekuensi } \\
(\mathrm{f})\end{array}$ & f.x & $\begin{array}{c}\text { Presentase } \\
(\%)\end{array}$ \\
\hline 1 & Sangat Setuju & 5 & 10 & 50 & 21,28 \\
\hline 2 & Setuju & 4 & 18 & 72 & 38,30 \\
\hline 3 & Kurang Setuju & 3 & 6 & 18 & 12,77 \\
\hline 4 & Tidak Setuju & 2 & 12 & 24 & 25,53 \\
\hline 5 & Sangat Tidak Setuju & 1 & 1 & 1 & 2,13 \\
\hline \multicolumn{2}{|c|}{ TOTAL (N) } & 47 & 165 & 100 \\
\hline \multicolumn{2}{|c|}{ Rata - rata skor $=\frac{\text { Jumlah f.x }}{\mathrm{N}}$} & $=\frac{165}{47}$ & 3,51 & \\
\hline
\end{tabular}

Sumber : Data Olahan 


\section{NAROTAMA JURNAL TEKNIK SIPIL \\ e-ISSN: 2460-3430}

VOLUME 3 NOMOR 1 JUNI 2019

Dari data diatas dapat dilihat bahwa 10 responden atau 21,28\% menjawab sangat setuju, 18 responden atau 38,30\% menjawab setuju, 6 responden atau 12,77\% menjawab kurang setuju, 12 responden atau 25,53\% menjawab tidak setuju, dan 1 responden atau 2,13\% menjawab sangat tidak setuju. Maka dari itu dapat ditarik kesimpulan bahwa masyarakat setuju jika Bangunan yang terbangun sudah mempunyai IMB dengan rata-rata skor 3,51.

Tabel 3 :Bangunan yang terbangun sudah sesuai dengan IMB dan peruntukanya

\begin{tabular}{|c|l|c|c|c|c|}
\hline No & \multicolumn{1}{|c|}{$\begin{array}{c}\text { Tanggapan } \\
\text { Responden }\end{array}$} & $\begin{array}{c}\text { Skor } \\
(\mathrm{x})\end{array}$ & $\begin{array}{c}\text { Frekuensi } \\
(\mathrm{f})\end{array}$ & f.x & $\begin{array}{c}\text { Presentase } \\
(\%)\end{array}$ \\
\hline 1 & Sangat Setuju & 5 & 4 & 20 & 8,51 \\
\hline 2 & Setuju & 4 & 22 & 88 & 46,81 \\
\hline 3 & Kurang Setuju & 3 & 10 & 30 & 21,28 \\
\hline 4 & Tidak Setuju & 2 & 11 & 22 & 23,40 \\
\hline 5 & Sangat Tidak Setuju & 1 & 0 & 0 & 0,00 \\
\hline \multicolumn{2}{|c|}{ TOTAL (N) } & 47 & 160 & 100 \\
\hline \multicolumn{2}{|c|}{ Rata - rata skor $=\frac{\text { Jumlah f.x }}{\text { N }}$} & $=\underline{160}$ & 3,40 & \\
\hline
\end{tabular}

Sumber : Data Olahan

Dari data diatas dapat dilihat bahwa 4 responden atau 8,51\% menjawab sangat setuju, 22 responden atau 46,81\% menjawab setuju, 10 responden atau 21,28\% menjawab kurang setuju, 11 responden atau 23,40\% menjawab tidak setuju. Maka dari itu dapat ditarik kesimpulan bahwa masyarakat setuju jika Bangunan yang terbangun sudah sesuai dengan IMB dan peruntukanya dengan rata-rata skor 3,40.

Tabel 4 :Pemilik atau pengguna bangunan akan mengurus izin kembali apabila ada perubahan pada bangunan

\begin{tabular}{|c|l|c|c|c|c|}
\hline No & \multicolumn{1}{|c|}{$\begin{array}{c}\text { Tanggapan } \\
\text { Responden }\end{array}$} & $\begin{array}{c}\text { Skor } \\
(\mathrm{x})\end{array}$ & $\begin{array}{c}\text { Frekuensi } \\
(\mathrm{f})\end{array}$ & f.x & $\begin{array}{c}\text { Presentase } \\
(\%)\end{array}$ \\
\hline 1 & Sangat Setuju & 5 & 7 & 35 & 14,89 \\
\hline 2 & Setuju & 4 & 18 & 72 & 38,30 \\
\hline 3 & Kurang Setuju & 3 & 18 & 54 & 38,30 \\
\hline 4 & Tidak Setuju & 2 & 4 & 8 & 8,51 \\
\hline 5 & Sangat Tidak Setuju & 1 & 0 & 0 & 0,00 \\
\hline \multicolumn{2}{|c|}{ TOTAL (N) } & 47 & 169 & 100 \\
\hline \multicolumn{2}{|c|}{ Rata - rata skor $=\frac{\text { Jumlah f.x }}{\mathrm{N}}$} & $=\frac{169}{47}$ & 3,60 & \\
\hline
\end{tabular}

Sumber : Data Olahan

Dari data diatas dapat dilihat bahwa 7 responden atau 14,89\% menjawab sangat setuju, 18 responden atau 38,30\% menjawab setuju, 18 responden atau 38,30\% menjawab kurang setuju, 4 responden atau 8,51\% menjawab tidak setuju. Maka dari itu dapat ditarik kesimpulan bahwa masyarakat kurang setuju jika pemilik atau pengguna 
bangunan akan mengurus izin kembali apabila ada perubahan pada bangunan dengan rata-rata skor 3,60.

Tabel 5 :Apabila tidak sesuai dengan izin yang telah ditentukan, pemilik atau pengguna bersedia menerima sanksi

\begin{tabular}{|c|l|c|c|c|c|}
\hline No & \multicolumn{1}{|c|}{$\begin{array}{c}\text { Tanggapan } \\
\text { Responden }\end{array}$} & $\begin{array}{c}\text { Skor } \\
(\mathrm{x})\end{array}$ & $\begin{array}{c}\text { Frekuensi } \\
\text { (f) }\end{array}$ & f.x & $\begin{array}{c}\text { Presentase } \\
(\%)\end{array}$ \\
\hline 1 & Sangat Setuju & 5 & 9 & 45 & 19,15 \\
\hline 2 & Setuju & 4 & 17 & 68 & 36,17 \\
\hline 3 & Kurang Setuju & 3 & 13 & 39 & 27,66 \\
\hline 4 & Tidak Setuju & 2 & 7 & 14 & 14,89 \\
\hline 5 & Sangat Tidak Setuju & 1 & 1 & 1 & 2,13 \\
\hline \multicolumn{2}{|c|}{ TOTAL (N) } & 47 & 167 & 100 \\
\hline \multicolumn{2}{|c|}{ Rata - rata skor $=\frac{\text { Jumlah f.x }}{\text { N }}$} & $=\frac{167}{47}$ & 3,55 & \\
\hline
\end{tabular}

Sumber : Data Olahan

Dari data diatas dapat dilihat bahwa 9 responden atau 19,15\% menjawab sangat setuju, 17 responden atau 36,17\% menjawab setuju, 13 responden atau 27,66\% menjawab kurang setuju, 7 responden atau $14,89 \%$ menjawab tidak setuju, dan 1 responden atau 2,13\% menjawab sangat tidak setuju. Maka dari itu dapat ditarik kesimpulan bahwa masyarakat setuju apabila tidak sesuai dengan izin yang telah ditentukan, pemilik atau pengguna bersedia menerima sanksi dengan rata-rata skor 3,55.

Dari kelima pernyataan yang menjadi indikator pada variabel ini, maka dapat disimpulkan secara umum besarnya nilai kepatuhan mengurus izin yang berlaku adalah sebagai berikut : 


\section{NAROTAMA JURNAL TEKNIK SIPIL \\ e-ISSN: 2460-3430 \\ VOLUME 3 NOMOR 1 JUNI 2019}

Tabel 6 :Nilai Kepatuhan Mengurus Izin yang Berlaku

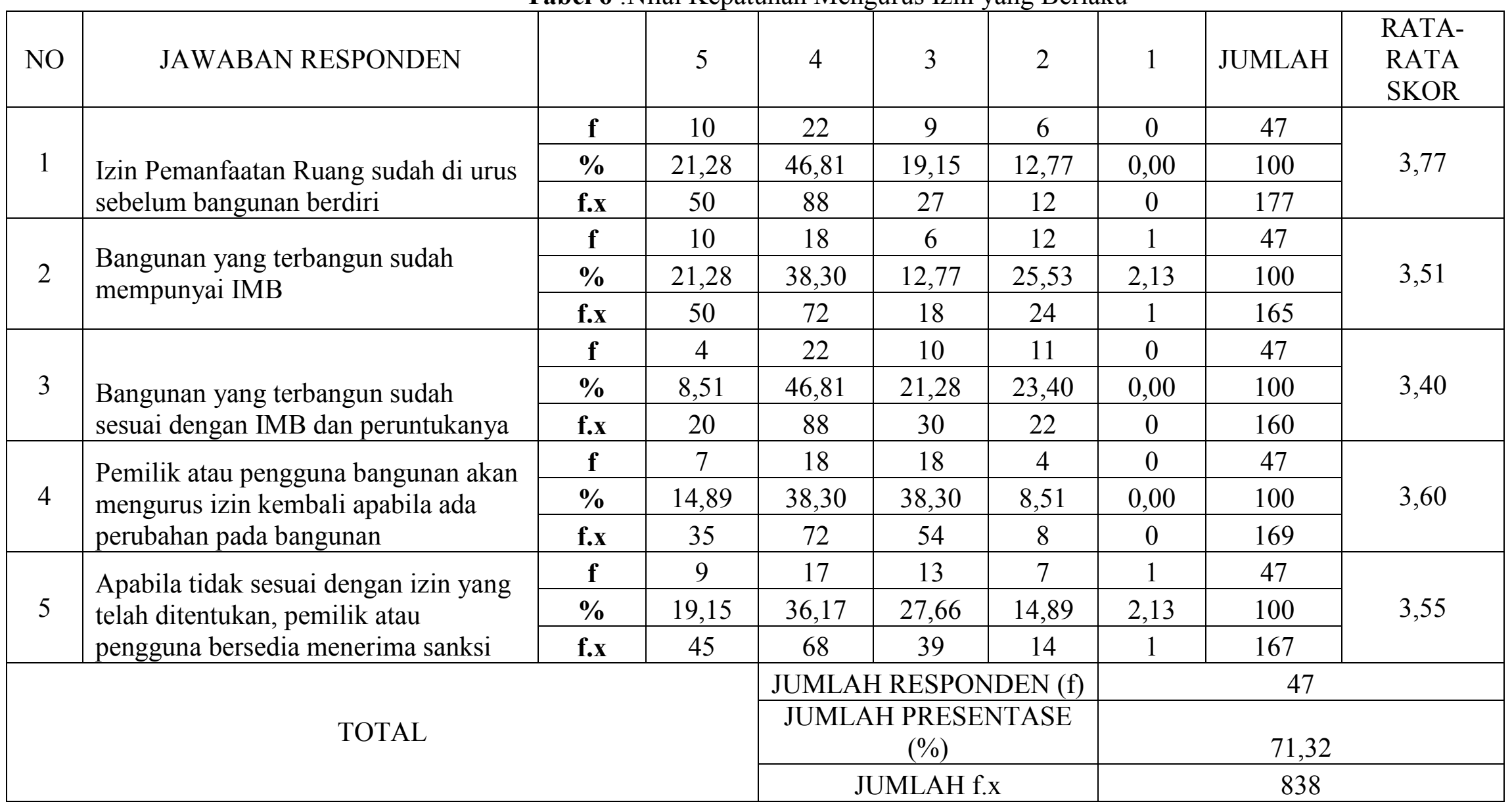

Sumber : Data Olahan 
Tabel 7 :Rentang NilaiKepatuhan mengurus izin yang berlaku

\begin{tabular}{|c|l|}
\hline RENTANG NILAI & \multicolumn{1}{|c|}{ KATEGORI } \\
\hline $235-423$ & Sangat Tidak Setuju \\
\hline $423-611$ & Tidak Setuju \\
\hline $611-799$ & Kurang Setuju \\
\hline $799-987$ & Setuju \\
\hline $987-1175$ & Sangat Setuju \\
\hline
\end{tabular}

Sumber : Data Olahan

Adapun jumlah nilai dari kelima indikator pada variabel kepatuhan mengurus izin yang berlaku ialah 838 atau $71,32 \%$ dari nilai tersebut dapat disimpulkan bahwa masyarakat kurang setuju atau banyak masyarakat yang kurang patuh dalam mengurus izin-izin sebelum mendirikan bangunan.

\section{KESIMPULAN}

Berdasarkan hasil penelitian yang telah dibahas diatas, maka dapat ditarik kesimpulan bahwa tingkat kepatuhan masyarakat dalam mengurus izin mendirikan bangunan diKabupaten Gresik sebesar 71,32\%. Untuk meningkatkan kepatuhan masyarakat dalam mengurus izin sebelum mendirikan sebuah bangunan, dengan cara memberikan sanksi-sanksi terkait setelah adanya sosialisasi. Pemda harus benar-benar lebih ketat dalam pemberian sanksi, agar hal ini dapat menimbulkan efek jera terhadap masyarakat. Sehingga bangunan liar yang ada di Kabupaten Gresik tidak semakin bertambah, dan tercipta masyarakat yang patuh dengan peraturan.

\section{DAFTAR PUSTAKA}

1. Amalia, Nurul. (2015). Akuntabilitas Pelayanan Izin Mendirikan Bangunan (IMB) Di Badan Perizinan Terpadu Dan Penanaman Modal Kota Makasar. Makasar: Skripsi Fakultas IlmuSosialdanIlmuPolitikUniversitasHasanuddin.

2. Arikunto, S. (2002). Prosedur Suatu Penelitian: Pendekatan Praktek. Edisi Revisi Kelima. Jakarta :PenerbitRinekaCipta.

3. Hafifah. (2012). Pelaksanaan Peraturan Daerah Nomor 15 Tahun 2004 Tentang Tata Bangunan Kota Makasar (Tentang Pemberian Izin Mendirikan Bangunan). Makasar :SkripsiFakultasHukumUniversitasHasanuddin.

4. Hidayat,Taufik. (2016). Contoh Proposal Skripsi Kuantitatif Pengaruh Model Pembelajaran Make A Match. Diambil dari: https://taufikhidayat93.blogspot.co.id/2016/04/contohproposal-penelitian-kuantitatif.html. (29 April 2017)

5. Husna, DinilladanBuchori, Imam. (2008). Instrumen Aturan-Aturan Dalam Pengendalian Pembangunan Kota di Surakarta. Surakarta : Jurnal TEKNIK Vol.29 No.1, ISSN 08521697.

6. Kabupaten Gresik. (2011). Peraturan Daerah No 28 Tahun 2011 tentang Bangunan Gedung. Gresik :DewanPerwakilan Rakyat Daerah.

7. Kurniawan, Deni. (2017). Contoh Bab 3 Skripsi Kuantitatif. Diambildari : http://www.phantomdeni.id/2017/04/contoh-bab-3-skripsi-kuantitatif.html (28 April 2017)

8. Permatasari, Tia Yuni. (2016). Metode Penelitian. Hlm 36-46. 
9. Sudirman, danFarid Muhammad. (2016). Analisis Penerimaan dan Pemahaman Masyarakat Terhadap Informasi Izin Mendirikan Bangunan di Kabupaten Maros. Sulawesi Selatan :JurnalKomunikasi KAREBA Vol.5.

10. Sugiyono. (2012). Memahami Penelitian Kualitatif. Bandung : ALFABETA.

11. Wahanisa, RofidanFibrianti, Nurul. (2013). Penyadaran Masyarakat Atas Pengurusan Izin Mendirikan Bangunan (IMB) Sebagai Peran Masyarakat Dalam Penataan Ruang Di Kelurahan Kalisegoro Kecamatan Gunungpati Kota Semarang. Semarang : Jurnal ABDIMAS Vol.17. 